\title{
ARGUMENT PLACEMENT IN FAROESE
}

\author{
BJÖRN LUNDQUIST \\ UiT The Arctic University of Norway
}

ABSTRACT

This article gives a summary of the Faroese data concerning argument placement in the Nordic Word order Database (NWD). Special emphasis is put on carefully describing the different conditions tested in the argument placement experiment, the experimental set-up, and the demographic information of the participants. An overview of relevant parts of Faroese grammar is also given, as well as a summary of the word order patterns found in the Faroese data present in the database. Finally, we discuss how the data in the database provides new insights to the grammar of Faroese, and how the data patterns in Faroese differ from the patterns observed in the other North Germanic languages.

\section{[1] INTRODUCTION}

This article summarizes the findings from fieldwork that took place in the Faroe Islands, August 2018, where in total 58 native speakers of Faroese participated in an elicited production experiment. ${ }^{1}$ The experiment covered various linguistic phenomena that fall under the category argument placement, e.g. object shift and particle shift. The experimental method is described in detail in the overview article of this special issue (Lundquist et al. 2019), and other syntactic variables covered in the data collection, mainly verb placement, are described in Westendorp (2020). In total 10.302 sentences targeting argument placement were recorded during the data collection. The sentences were subsequently annotated for word order. All the annotated sentences and their corresponding sound files are available in the Nordic Word order Database (henceforth referred to as NWD).

[1] The field work was funded by the RCN project Variation and Change in the Scandinavian Verb Phrase (project number: 250755, PI: Ida Larsson). The data collection was carried out by Ida Larsson, Filippa Lindahl, Björn Lundquist, Annika Simonsen, Eirik Tengesdal and Maud Westendorp. Research time for Björn Lundquist was funded by the RCN project Experimental approaches to Syntactic Optionality (project number 302524, PI: Björn Lundquist). 
Although Faroese syntax is well-studied (e.g., Barnes 2001, Svenonius et al. 2009, Thráinsson et al. 2012, Thráinsson et al. 2017), there are still many phenomena that are not well-documented, and comparisons with the other North Germanic languages are not always easy to make. For example, the restrictions on object shift (NP and pronominal), particle shift and embedded V2 and V-to-I are all syntactic phenomena that have been investigated for Faroese, but we have few direct comparisons with the other North Germanic languages. Much of the previous research is based on grammaticality judgements, and, as has been shown in several studies on Faroese, there is a lot of gradience in the judgements (Thráinsson 2009, Heycock et al. 2010). It is sometimes unclear if this gradience is the result of some participants accessing more "archaic" or formal registers when they evaluate sentences. In a production task, participants are more likely to stay within one register, and the results obtained are more likely to reflect the way their language is used in everyday situations. The frequencies of different structural realizations reported on in this article will be directly comparable to frequencies from the other North Germanic languages, as can be obtained directly from the NWD web interface, or from the other articles in this volume.

The structure of the article is the following: Section 2 contains a brief description of Faroese syntax with a focus on the syntactic properties covered in this article (i.e., argument placement). Section 3-4 describes the material and the setup of the experiment, and Section 5 gives an overview of the participants. In Section 6 , the core results of the experiments are presented, followed by a discussion and conclusions.

[2] FAROESE syntax, With a FOCUS ON SUBJECT-, OBJECT- AND PARTICLE PLACEMENT

There is an estimated number of 69,000 speakers of Faroese, of which 48,000 live in the Faroe Islands. There is also a large population of Faroese speakers in Denmark (https://www.ethnologue.com/country/fo/languages). Faroese speakers learn Danish in school, and most speakers are proficient Faroese-Danish bilinguals. This has had an effect on the Faroese lexicon, and possibly the syntax as well (see Petersen 2010 and Thráinsson 2017 for discussion). In addition, most younger speakers are proficient in English.

Faroese shares many syntactic traits with the other Scandinavian languages, such as strict VO and prepositions rather than postpositions. Faroese is a V2 language, and it seems to have developed into an asymmetric V2 language: V2 is obligatory in main clauses, but optional in many subordinate contexts. Many speakers also find V2 impossible in some subordinate contexts, similar to the situation in the Mainland North Germanic languages (Jonas 1996, Bentzen et al. 
2009, Heycock et al. 2010), although as Thráinsson (2017) notes, some speakers accept V2 in all types of embedded clauses.

Like Icelandic and unlike the standard Mainland North Germanic varieties, Faroese still has a morphological case system, and person and number agreement on verbs, although this system has a reduced number of contrasts compared to Icelandic. A great deal of research on Faroese has focused on the relationship between the morphological system and the syntax, especially how an impoverished inflectional system (both verb agreement and case) may correlate with the loss of syntactic properties like V-to-T movement, stylistic fronting and NP object shift (see especially Thráinsson 2009 for an in-depth discussion). NP object shift will be discussed below, but otherwise, this article covers a different set of variables.

The first syntactic variable targeted in the present study is the placement of post-verbal subjects. Much of the discussion about subject placement in Faroese has centered around the availability of a low subject position, mainly hosting indefinite subjects in transitive expletive constructions (Bobaljik and Jonas 1996, Thráinsson 2017). NWD does not contain any data on expletive constructions. Rather, almost all subjects in this study are either pronouns or definite noun phrases (mainly names and occupational nouns). The core variation that is targeted is the placement of non-quantificational noun phrases with respect to a negation or a sentential adverb.

As discussed in for instance Holmberg (1993), Jonas (1993) and Svenonius (2002), there is some variation within the North Germanic languages with respect to subject placement. Definite noun phrases are obligatorily placed before negation in Danish (with the possible exception of constituent negation), while they preferably, but not obligatorily, are placed after negation in Norwegian (see e.g. Anderssen et al. 2018). In Swedish, definite noun phrase subjects appear to be equally acceptable before and after a negation. The difference between the Swedish and Danish is illustrated in (1) below, where curly brackets are used to indicate possible/impossible placement of the subject.

$\begin{array}{llllll}\text { a. I går spiste } & \text { \{læreren\} } & \text { ikke } & \text { (*læreren\} } & \text { frokost. } & \text { DAN } \\ \text { b. Igår åt } \quad \text { Iläraren }\} \text { inte }\{\text { läraren } & \text { lunch. } & \text { SWE } \\ \text { y.day ate teacher.DEF not teacher.DEF } & \text { lunch } & \\ \text { 'Yesterday, the teacher did not eat lunch.' } & & \end{array}$

Icelandic has a system more like the Danish one, i.e., a subject in the TP/IP domain is placed before negation, but as discussed in Vangsnes (1995), quantified subjects may appear in a low position. Jonas (1993) reports on a potential split 
between two lects in Faroese; one that behaves like Norwegian, and one that behaves like Icelandic. The b-sentence below is thus only available in the first variety (example from Jonas 1993):

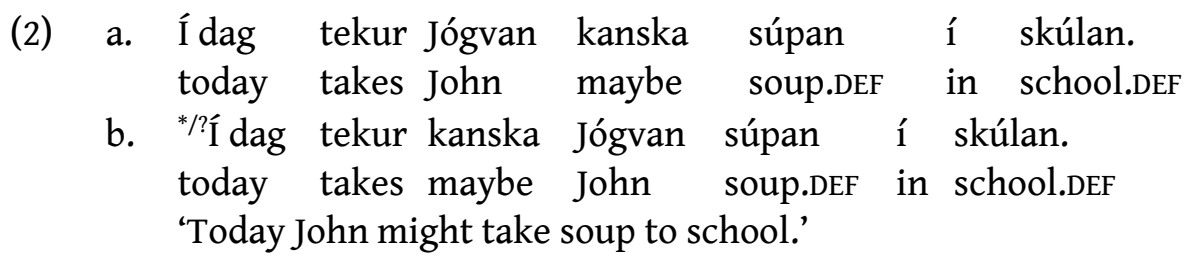

Jonas (1993) analyzes the variation of the subject-adverb ordering as variation in adverb placement, rather than as an availability of several subject positions, but see Svenonius (2002) for criticism of this analysis.

The second core syntactic variable tested in the experiment is object shift, i.e., the shifting of a syntactic object to a position in the IP/TP, preceding sentential adverbs, in the context of movement of the main verb to the V2 position (Holmberg 1986). All Scandinavian languages allow some kind of shifting of light pronominal objects, but they differ in how obligatory the shifting is. Swedish is usually taken as a language with optional pronominal object shift, whereas the other languages have more or less obligatory pronominal object shift (with regional or context dependent exceptions, see e.g. Andréasson 2008, Bentzen 2014, Bentzen \& Anderssen 2019). We illustrate the word order options in (3), here contrasting Faroese and Swedish. Note that all Scandinavian varieties allow unshifted pronominal objects, as long as they are contrastive.

\begin{tabular}{|c|c|c|c|c|c|c|}
\hline 3) a. & Lærarin & hjálpti & $\{\mathrm{mær}\}$ & ikki & $\left\{{ }^{*} \mathrm{mær}\right\}$ & við \\
\hline b. & $\begin{array}{l}\text { Läraren } \\
\text { teacher.DEF }\end{array}$ & $\begin{array}{l}\text { hjälpte } \\
\text { helped }\end{array}$ & $\begin{array}{l}\text { mig\} } \\
\text { me }\end{array}$ & $\begin{array}{l}\text { inte } \\
\text { not }\end{array}$ & $\begin{array}{c}\{\mathrm{mig}\} \\
\text { me }\end{array}$ & $\begin{array}{l}\text { skúlatingunum } \\
\text { med läxan. } \\
\text { with home- } \\
\text { work.DEF }\end{array}$ \\
\hline
\end{tabular}

'The teacher did not help me with the homeworks'

Object shift is restricted to light pronominal objects in Mainland North Germanic, and shifting of phrasal objects (NPs ${ }^{2}$ ) is strictly ungrammatical (see Swedish example in 4a). Shifting of NP objects is found in Icelandic where it appears to be optional and governed partly by factors like definiteness and specificity (4b), see Larsson (forthcoming) for discussion of Icelandic NP object shift.

[2] We will refer to phrasal subjects and objects as NP's, and pronominal subjects and objects as pronouns or pronominal subjects/objects. 
(4)
a. Läraren
hjälpte
$\{*$ Åsa $\}$ inte $\{$ Åsa $\}$
igår.
SWE
b. Kennarinn
hjálpaði
\{Asa\} ekki $\{$ Asa\}
teacher.DEF
helped
Åsa not ̊̊sa
'The teacher did not help Asa yesterday.
ígær
ICE
yesterday

It is less clear if or to what extent NP object shift is allowed in Faroese. The consensus though is that NP object shift is much more limited in Faroese compared to Icelandic, and possibly totally absent (see Barnes 1992, but also Thráinsson 2013 for a slightly different view and extensive discussion). Faroese further lacks so-called long object shift, i.e. the shifting of an object over a subject in the IP/TP (see example 5 below). Long object shift is probably restricted to Swedish among the North Germanic languages.

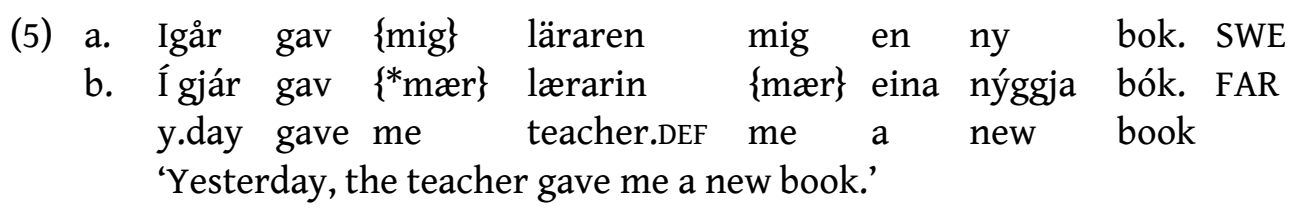

The third core syntactic pattern tested is placement of verb particles. Like the other Germanic languages, verb particles in Faroese stay inside the VP, and are not expected to invert with e.g. a sentence adverb or a (VP-external) subject.
(6) Í gjár ruddaði $\left\{{ }^{*} u p p\right\}$
y.day cleaned up
næmingurin \{upp\} í køkinum.
student.DEF up
in kitchen.DEF
'Yesterday, the student cleaned up in the kitchen.'

Note that although this is the standard pattern in all the North Germanic languages, deviations have been found in Norwegian and Swedish in both spontaneous and elicited speech, mainly from children and teenagers (Hanne Siri Sund p.c., Tina Ringstad p.c., and personal observations). ${ }^{3}$ In the current study, we include several items that target the relationship between subjects and verb particles. Although we expect little or no variation in the ordering of subjects and particles, it may tell us something about particle prosody. Verb particles tend to form prosodic units with the verb, but still little is known about how syntactic distance and intervening material affect the verb-particle prosodic unit.

In the experiment, we include four different verb-particle configurations illustrated by the examples in (7) below involving the particle verb rudda upp

[3] For example, a Swedish speaking 8 year old regularly produced sentences with the structure XP V Part Sub, as in då hoppade över jag två stycken (lit. 'Then jumped over I two pieces.' - then I jumped over two pieces). Hanne Siri Sund provided me with several examples from Trondheim teenagers, e.g. og då kjørt inn han i en sånn strømboks (lit. 'and then drove in he in an electricity box.' - and then he collided with one of those electricity boxes) 
('clean up'): (i) Verb and particle adjacent in the verb phrase (+linear adjacency, +syntactic proximity, cf. 7a); (ii) verb in V2 position, particle in VP without interveners (+linear adjacency, -syntactic proximity, cf. $7 \mathrm{~b}$ ); (iii) verb in V2 position, particle in VP with an intervening unstressed pronoun (-linear adjacency, syntactic proximity, -intervening tone-bearing units, cf. 7c), and (iv) verb in V2 position, particle in VP with an intervening phrase (-linear adjacency, -syntactic proximity, +intervening tone-bearing units, cf. $7 d$ ).
a. Hann fer at [rudda upp] í køkinum.
b. Hann [ruddaði upp] í køkinum í gjár.
c. Í gjár [ruddaði hann upp] í køkinum í gjár.
d. Í gjár [ruddaði næmingurin upp] í køkinum.
'He/the student cleaned/will clean up in the kitchen (yesterday)'

We have yet not attempted to do a careful analysis of the prosodic units in the material, but this will hopefully be done in the near future, with comparisons between the North Germanic languages.

Although the ordering between subject and particle is stable, Faroese has been claimed to have variable linearization of particles and direct objects (Thráinsson et al. 2012, p. 247), similar to the variation found in Norwegian and English: light pronominal objects precede particles ("throw it out") while NP objects often follow the particle ("throw out the garbage"). Note however that both Sandøy (1976, p. 95) and Svenonius (1996, p. 15) claim that particle placement is less variable in Faroese compared to Norwegian and English, and that the Faroese system rather is similar to Danish, where particles obligatorily follow both pronouns and noun phrase objects.

In the results section (Section 6), more Faroese examples of the phenomena discussed above will be presented and discussed.

\section{[3] MATERIAL}

The argument placement experiment contained 86-92 elicited sentences per participant. The original experiment contained 92 items, but 6 items were removed from the experiment after the second day of fieldwork, due to a high error rate of these items (mainly due to problems with interpreting non-human referring pronouns in isolated sentences). The experiment consists of three parts, described in detail in the overview article (Lundquist et al. 2019).

In the first part, the participant is presented with a subject-initial sentence (the so-called background sentence) on a computer screen, and is asked to read this sentence aloud. This is followed by the appearance of the so-called trigger, which is the start of a new sentence. The participant is asked to complete the 
sentence, using the same material as in the background sentence. An example is given in example (8) below, where the material in parentheses in $(8 b)$ is what the participant is expected to produce.
a. Lærarin tók bussin til arbeiðis gjár. teacher.DEF took bus.DEF to work yesterday
(background) 'The teacher always took the bus to work.'
b. Ígjár... (tók leerarin bussin til arbeiðis.) yesterday.. took teacher.DEF bus.DEF to work 'Yestderday, the teacher took the bus to work.'
(trigger)

In the test material, the finite verb is followed by either a negation, a particle or a direct object. In the subsequent analysis of the material, we annotate the placement of the subject in the produced sentence: does it directly follow the verb, or does it appear after the post-verbal element? This translates directly to information about the syntactic variables under investigation: subject shift, long object shift and long particle shift.

In the second part, the participant is presented with a subject-initial sentence with a complex tense, usually a future tense. The following trigger contains an adverb and a finite main verb, as in (9a-b) below (followed by the expected realization in parentheses).
a. Rennarin fer at vaska sær aftan á renninginna runner.DEF will to wash self after PREP run.DEF 'The runner will wash himself after the run.' yesterday washed runner.DEF self after PREP run.DEF 'Yesterday, the runner washed himself after the run.'
b Ígjár vaskaði... (rennarin sær aftan á renningina.)

In the experiment, the main verb is followed by a particle or a pronominal direct object, and in some conditions, a negation is inserted after the finite auxiliary. In the analysis, we annotate placement of subject, object, negation and particle. This directly gives us information about long- and regular object shift, subject shift and long particle shift (i.e., the shifting of a particle over a non-initial subject).

In the third part, the background sentence is a subject-initial passive sentence, and the trigger is the start of an active sentence (subject plus finite main verb): 
a. Teir vórðu handtiknir av løgregluni ígjár. (background) they were arrested by police.DEF yesterday 'They were arrested by the police yesterday.'

b Løgreglan handtók (teir í gjár). police.DEF arrested them yesterday 'The police arrested them yesterday.'

The sentences in the experiment contain either a negation or a particle, and in the analysis, we annotate whether the object in the produced sentence appears before or after the negation/particle. By doing this we get information about object shift and particle shift.

Table 1 gives an overview of the experiment, and the number of items in each condition. In the conditions where the number of items changed throughout the field work, the number of items is given for both settings.

\begin{tabular}{|c|c|c|c|}
\hline Part & Phenomena & Sub cond 1. & Sub cond 2. \\
\hline \multirow{7}{*}{$\begin{array}{l}\text { 1.Subject-Verb in- } \\
\text { version }(n=34,36)\end{array}$} & \multirow{2}{*}{ Subject shift $(n=10)$} & NP subj $(n=5)$ & \\
\hline & & Pro subj $(n=5)$ & \\
\hline & \multirow{3}{*}{ Long object shift $(\mathrm{n}=15)$} & \multirow{2}{*}{ NP subj $(n=10)$} & Refl. Obj. (5) \\
\hline & & & $1^{\text {st }}$ pers Obj (5) \\
\hline & & Pro subj $(n=5)$ & Refl. Obj (5) \\
\hline & \multirow{2}{*}{ Subject-Particle $(n=9,11)$} & NP subj $(n=5,6)$ & \\
\hline & & Pro subj $(n=4,5)$ & \\
\hline \multirow{4}{*}{$\begin{array}{l}\text { 2. Subject-verb in- } \\
\text { version, complex } \\
\text { to simple tense } \\
\qquad(n=20)\end{array}$} & \multirow{2}{*}{$\begin{array}{c}\text { Subject shift, (long) ob- } \\
\text { ject shift }\end{array}$} & NP subj $(n=5)$ & Refl. Obj (5) \\
\hline & & Pro subj $(n=5)$ & $1^{\text {st }}$ pers Obj (5) \\
\hline & \multirow{2}{*}{ Subject-Particle $(n=10)$} & NP subj $(n=5)$ & \\
\hline & & Pro subj $(n=5)$ & \\
\hline \multirow{4}{*}{$\begin{array}{l}\text { 3. Passive to active } \\
\qquad(n=32,36)\end{array}$} & \multirow{2}{*}{ Object shift $(n=10)$} & NP obj $(n=5)$ & \\
\hline & & Pro obj $(n=6)$ & \\
\hline & \multirow{2}{*}{ Particle shift $(\mathrm{n}=21,25)$} & NP obj $(n=11,13)$ & See Section \\
\hline & & Pro obj $(n=10,12)$ & 5.3 \\
\hline
\end{tabular}

TABLE 1: Overview of material in the experiment. 
The individual test sentences were modelled after sentences used in Swedish and Norwegian experiments. Translation was done by Zakaris Svabo Hansen and Jóhannes Gísli Jónsson. Part 1 and 2 had been piloted with a test group of eight participant by Julian Kirkeby Lysvik. Some sentences were replaced after this round. All three parts were later piloted by Jóhannes Gísli Jónsson. The results from the pilot experiments did not differ in a noticeable way from the results from the main experiment.

\section{[4] EXPERIMENTAL SETUP ${ }^{4}$}

The experiments were run on laptops using the software OpenSesame (Mathôt et al. 2012). We used handheld digital audio recorders (Zoom H2n/H4/H4nPro Handy Recorder) to record the sessions. A limited number of recordings was made with an external lapel microphone (Audio-Technica ATR3350/AT8532), but most recordings were made using the recorder microphone(s). The recordings were made in WAV-format at $44,1 \mathrm{kHz}$ audio sampling rate, with a bit depth of 16. Due to some technical difficulties, some recordings on the first day of testing were made in a lower quality mp3-format.

Data collection took place in Tórshavn (August 23, 2018), Fuglafjørður (August 24) and Klaksvík (August 26-27). Arrangements were made with contact persons or teachers at the different locations in advance so that people were recruited to participate and so that we were given access to rooms for conducting the experiment. The experiment was always conducted individually, in a separate room. A number of different researchers and research assistants conducted the experiment (see acknowledgements). The large team allowed us to test three or more participants at the same time. Instructions were provided mostly in Norwegian or Swedish, and sometimes in Faroese. If anything remained unclear, English was used to make sure that the participants understood the task.

\section{[5] PARTICIPANTS}

58 native Faroese speakers participated in the experiment. 11 of these also participated in the verb placement experiment, covered in Westendorp (2020). Many of the participants were students from high schools in Fuglafjørður, Klaksvík, Tórshavn. In addition, we recruited older participants by putting out a call on Facebook. In one of the locations, Fuglafjørður, we had only young participants ( $<20$ years old), but in the other locations, participants from the entire age range took part. The locations of the field work sessions are marked in the map in Map 1 below.

[4] A similar methods part is presented in Westendorp 2020, as the data collection for the two articles took place during the same field work sessions. 


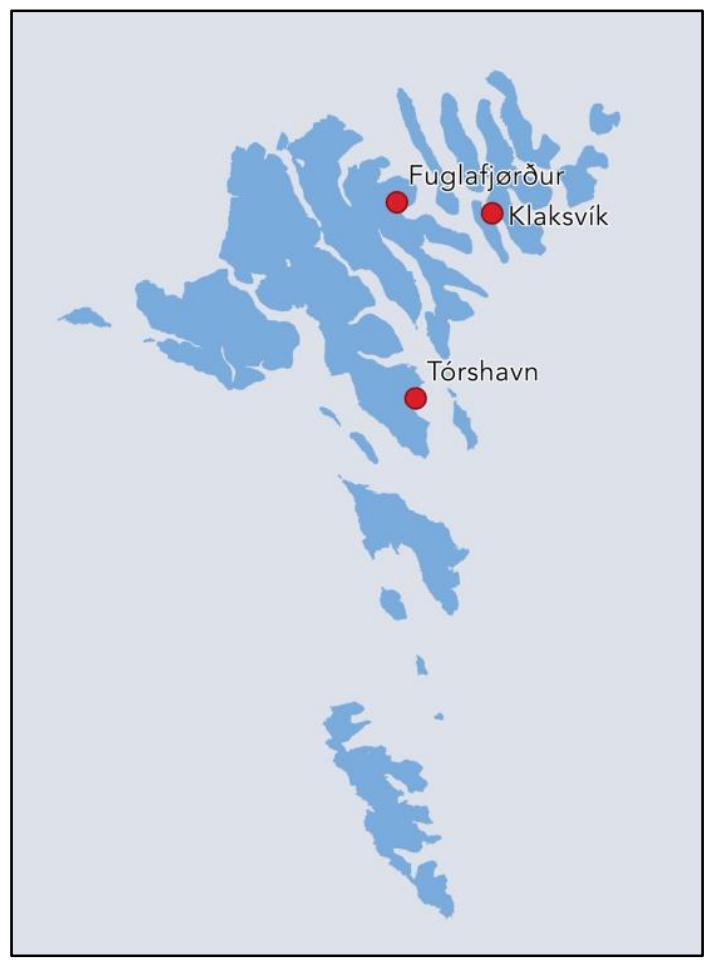

All participant volunteered to participate. The high school students received a small gift as a thank you for their time. All participants had Faroese as their first language; three participants had additional, simultaneously acquired, first languages (English/Danish). An overview of the participants is given in Table 2 below.

MAP 1: Overview of fieldwork locations on the Faroe Islands.

\begin{tabular}{cccc}
\hline Location & $\begin{array}{c}\text { Number of } \\
\text { participants }\end{array}$ & $\begin{array}{c}\text { Gender } \\
\text { (male/female) }\end{array}$ & $\begin{array}{c}\text { Age range } \\
\text { (mean) }\end{array}$ \\
\hline Tórshavn & 13 & $(3 / 10)$ & $18-60(28,7)$ \\
Fuglafjørður & 19 & $(6 / 13)$ & $17-20(18,8)$ \\
Klaksvík & 26 & $(17 / 9)$ & $17-65(31,1)$ \\
\hline Total & $\mathbf{5 8}$ & $\mathbf{( 2 6 / 3 2 )}$ & $\mathbf{1 7 - 6 5 ( 2 6 , 5 )}$ \\
\hline
\end{tabular}

TABLE 2: Overview of participants.

\section{[6] Results}

In section 6.1-6.4 below, the result from the experiment will be presented, focusing on one core variable per section. A summary of the results is given in tables 3-4 in section 6.5. 


\section{[6.1] Subject placement with respect to adverbs}

Subject shift refers to the placement of the syntactic subject with respect to a sentence adverb. In the experiment, we only tested the placement of subjects with respect to negation. In the online search interface of the Nordic Word order Database, the subject shift items can be found by selecting SS under the "exact category" tab.

Subject shift was tested in both the first and the second part of the experiment. In the first part, participants read a subject initial sentence containing a negation (11a), and were then cued with a sentence initial adverbial like for instance ígjár 'yesterday'. We expect the Faroese participants to place the subject right between the verb and the negation, as in (11b), and not after the negation, as in (11c) (which would be the most common structural choice in for instance Norwegian).
a. Lærarin tók ikki bussin til arbeiðis ígjár. teacher.DEF took not bus.DEF to work yesterday 'The teacher didn't take the bus to work yesterday.'
b. Í gjár... tók lærarin ikki bussin til arbeiðis. y.day took teacher.DEF not bus.DEF to work 'Yesterday, the teacher didn't take the bus to work.'
c. Í gjár... tók ikki lærarin bussin til arbeiðis. y.day took not teacher.DEF bus.DEF to work 'Yesterday, the teacher didn't take the bus to work.'

The experiment contained five items of the type above, and also five items with pronominal subjects instead of full NP subjects. The Faroese participants performed as expected in: 566 out of 571 elicited sentences, the subject was placed in front of the negation as in (11b). In the remaining five, the participants accidentally left out the negation. Not a single attestation of the order negation-subject was found (i.e., the word order in 11c).

In part 2 of the experiment, subject placement was tested with respect to both negation and light reflexive objects. Here, the participant reads a sentence with a complex tense, like the periphrastic future in (12a), containing both a negation and reflexive object. The negation obligatorily surfaces directly after the finite auxiliary, and the reflexive after the main verb. The trigger consists of a fronted adverb followed by a finite main verb, as in (12b). The participant then finishes the trigger sentence, now with the subject, negation and reflexive adjacent to each other. The sentence in (12b) gives the expected order in Faroese, but note that all six logically possible orders could in principle be found in a language with variable subject and object placement as in Swedish (see Lundquist et al. 
2019). This condition is labeled SSRefl under the Exact Category tab in the search interface.

(12) a. Rennarin fer ikki at vaska sær aftan á renninginna runner.DEF will not to wash self after PR run.DEF 'The runner will not wash himself after the run.'

b. Ígjár vaskaði ... rennarin scer ikke aftan á renningina. y.day washed runner.DEF self not after PR run.DEF 'Yesterday, the runner did not was himself after the run.'

The experiment contained five items of the type above, all with NP subjects. Out of 290 collected responses, 262 had the order subject-reflexive-negation, i.e. the order exemplified in (12b). The remaining 28 cases included errors of some kind. The errors consisted of leaving out the negation or substituting the noun phrase subject with a pronoun. In one single case the reflexive is left out. In the produced sentences with errors, we still never find any cases where the subject is preceded by the negation or the reflexive. We can safely conclude that the order subject-negation is very strict in Faroese, similar to Icelandic and Danish (again, see Lundquist et al. 2019).

In part 2 of the experiment, placement of pronominal subjects with respect to negation and (non-reflexive) pronominal objects was also tested. This is discussed below in the section about object shift (6.3).

\section{[6.2] Subject placement with respect to particles}

The experiment contained many items that tested the placement of subjects with respect to verb particles. As discussed in section 2 above, we do not really expect any variation within the North Germanic languages with respect to subject-particle order: particles surface inside the verb phrase, and subjects (at least definite subjects) surface outside the VP (in TP or CP).

The subject-particle order was tested in both part 1 and part 2 . The test items were similar to the items in 7-8 above, with a particle instead of an adverb in part 1 and a particle instead of a reflexive in 2 . We illustrate the sentence type used in part 1 in the 13 below:

(13) a. Næmingurin ruddaði upp í køkinum ígjár. student.DEF cleaned up in kitchen.DEF yesterday 'The student cleaned up in the kitchen yesterday'

b. Í gjár ruddaði næmingurin upp í køkinum. y.day washed student.DEF up in kitchen.DEF 'Yesterday, the student cleaned up in the kitchen.' 
A negation was never present in the items in part 1 or 2, i.e., we never tested the relative order of negation and particle. Unsurprisingly, we didn't find a single instance of the order Particle-Subject. There is a fairly low proportion of errors (77 of a total of 1153), which consist mainly of dropped particles or substitutions of noun phrases with pronouns. No errors involved placing a particle before a subject. The subjects were either full noun phrases or pronouns; in table 3 in section 6.5, the exact numbers for pronouns and NP subjects are given. In the database online interface, the sentences that test the placement of subjects with respect to particles can be found by selecting "Subject-Particle" under the Pairscolumn, or choosing "Part-Sub" under Exact category.

\section{[6.3] Regular and long object shift}

Regular object shift is tested in part 2 and part 3 of the experiment. In part 2, object shift with light reflexive objects and first person pronominal objects are tested, as exemplified in example 8 above. Here, we get information about both subject shift and object shift. As we saw, the only attested order was subjectreflexive-negation, i.e. object shift with a light reflexive object, appears to be obligatory. Shifting of first person pronominal objects is tested in a similar setting, but in this condition, the grammatical subject is also a pronoun (14):
a. Hann fer ikki at geva mer nýtt breyð.
He will not to give me new bread
'He will not give me fresh bread.'
b. Í gjár gav... hann mor ikki nýtt breyð. y.day gave he me not fresh bread 'Yesterday, he didn't give me fresh bread.'

Here, a fronted adverb and a finite verb are given in the trigger. The variable we are interested in is the order of subject, object and negation. However, since shifting of pronominal subjects around negation is obligatory in Faroese, we focus on the order of object and negation in the following. We included five items in the first person object condition. Out of the total 290 elicited sentences, 265 have the produced order subject-object-negation (exemplified in 14b). 21 examples contain an error of some kind; almost exclusively the negation or the object is missing. There are in total three examples of the order subject-negation-object. Whether this should be seen as production errors or naturally occurring variation is hard to tell. In addition, we find one example of the order objectsubject-negation.

Part 3 tests object shift of third person pronouns and noun phrases. Here, the 
background sentence is a passive sentence, with the underlying internal argument realized as a subject in first the position (pronoun or NP, 15a/16a). The trigger consists of a finite active verb, preceded by the subject/agent of the clause (15b/16b). The verb may then be followed directly by the object, or the negation; the two options of placement of the object is given in curly brackets in $15 \mathrm{~b} / 16 \mathrm{~b}$. It could be argued that this condition is more complex and challenging than the conditions in part 1 and 2, since the participants not only have to manipulate the word order, but also, in some cases, have to adjust the case marking of the object/theme (e.g., singular $3^{\text {rd }}$ person feminine pronouns). We cannot see any obvious signs of processing difficulties triggered by case marking, but it is still worth keeping this in mind when analyzing the results.

(15) a. Teir vórðu ikki handtiknir av løgregluni ígjár. They were not arrested by police.DEF yesterday 'They were not arrested by the police yesterday.'

b. Løgreglan handtók (\{teir\} ikki \{teir\}) ígjár). police.DEF arrested them not them yesterday 'The police arrested them yesterday.'

(16) a. Tjóvarnir vórðu ikki handtiknir av løgregluni ígjár. thieves.DEF were not arrested by police.DEF yesterday 'They were not arrested by the police yesterday.'

b. Løgreglan handtók (\{tjóvarnir\} ikki tjóvarnir ígjár). police.DEF arrested thieves.DEF not thieves.DEF yesterday 'The police did not arrest the thieves yesterday.'

Six items with third person pronominal objects were included per participant. Here we find in total 24 attestations of the order negation-object, compared to 291 attestations of object-negation (see the two orders in 15b). This is a non-negligible amount of variation. It is unclear if the variation is conditioned by information structure or phonological factors, or if there is some amount of free, random variation. The examples of negation-object order are easy to access from NWD interface, and readers may themselves evaluate to which extent the attested examples sounds like speech errors. For a non-native listener, some of the examples show signs of disfluent speech and include hesitations, but in most examples, the sentences are produced in a fluent manner, and the object pronoun appears to be genuinely unstressed.

We find only very few attestations of NP object shift: in total there are eleven instances of noun phrase objects preceding a negation, compared to 280 attestation of the order negation-NP. Again, it is not clear if the cases of NP object shifts 
should be seen as production errors or licit variation. It should be noted that most cases of NP object shift occurs with one specific item, which is an object experiencer verb (Hendan nýggja fløgan hugtók ummalaran ikki. 'The new show did not impress the critic'). We will return to this result in the discussion part.

The items that tested subject shift and object shift in part 2, also tested for the placement of objects with respect to subjects, i.e., long object shift. As was discussed in Section 6.1, we found no instances of light reflexive objects preceding NP subjects, and only one instance of a first person object pronoun preceding a pronominal subject. In part 1 of the experiment, long object shift with reflexive or first person pronominal objects and NP subjects is tested. The background sentence was a subject initial clause with a finite main verb followed by a pronominal object (7a), and the trigger consisted only of a sentence initial adverb. Most items were double object structures, since an indirect object is possibly more likely to undergo long object shift than direct objects. An example of a background sentence (17a) followed by a trigger and the expected produced word order (17b) is given below.
a. Lorarin gav mær eina nýggja bók ígjár. teacher.DEF gave me a new book yesterday 'The teacher gave me a new book yesterday.'
b. Ígjár gav (\{mær\} loerarin $\quad\{$ mær $\}$ eina nýggja bók y.day gave me teacher.DEF me a new book 'Yesterday, the teacher gave me a new book.'

We included five items with first person singular objects, and five with reflexive objects. There were no attestations of the order object-subject. Only 11 errors were found. See table 3-4 for exact numbers, and comparisons. In the online database, items that test object shift are easily accessed by choosing either Negation - Object, or Subject - Object under the Pairs-tab.

\section{[6.4] Particle shift}

In total 21 items were included in part 3 to test the placement of particles with respect to a direct object. In contrast to most other phenomena tested in the database, we included many sub-conditions for particle shift, sometimes with only one item of each sub-condition. This choice was made based on the fact that particle shift is dependent on many factors. We will go through the different conditions below.

It is well-known that several linguistic factors influence particle shift, most obviously the form of the direct object: pronominal objects are expected to precede particles to a higher degree than noun phrases. Furthermore, particles that 
co-occur with a directional prepositional phrase may be more likely to follow direct objects (e.g., "He threw him up into the air", see e.g. Larsson and Lundquist 2014 for discussion). It is also possible that the semantic relationship between verb and particle influences the placement preferences: a highly idiomatic meaning of the verb-particle combination may increase the likelihood of adjacency between verb and particle (e.g., "check out" vs. "take out"). Finally, the semantic relationship between the particle and the object may influence ordering: when the particle assigns the thematic role Ground rather than Figure (see Svenonius 2003), the particle may behave more like a preposition, preceding the direct object, for example, he stepped off the bus (bus = Ground) vs. he rubbed off the stain (stain = Figure). We therefore manipulated all the factors mentioned above. In the search interface of the Nordic Word order Database, the results can be filtered as to include only NP or pronominal objects, particles with or without directional PPs, non-spatial/non-transparent verb-particles and particles with Ground complements.

The set up for all of the sub-conditions is the same. The participants read a passive background sentence, with the internal argument in the first position. The passivized verb is always followed by a particle (18a). The trigger consists of a finite active main verb preceded by the agent/subject. The participant has to place the object either before or after the particle, see placement options in (18b):

a. Studenturin varð blakaður út av barrini av duravørðunum student.DEF was thrown out of bar.DEF by guard.PL.DEF 'The student was thrown out of the bar by the guards.'

b. Duravørðirnir blakaðu (\{studentin\} út \{studentin\} av barrini.) guard.PL.DEF threw student.DEF out student.DEF of bar.DEF 'The guards threw the student out of the bar.'

The results show a surprisingly small amount of variation. In total 1229 sentences with objects preceding particles were elicited, and only three instances of the opposite order. 91 errors appeared, most of which usually involved a missing particle or a substitution of a noun phrase with a pronoun. The particle-object order in Faroese thus seems equally strict as in e.g. Danish. Among the three examples with the reverse order, only two have a normal intonational pattern, and they are both examples with Ground-taking particles. The different types of object-particle items can be accessed in the online database, by selecting Object Particle under the Pairs-tab, and further select the type of object under TypeElement1 (pronoun or NP), and the type of particle under TypeElement2. 


\section{[6.5] Summary of the results}

The results are summarized in table 3-4 below. Table 3 covers all the results where the placement of the subject is the core variable (placement of subject with respect to negation, particles and objects), and table 4 covers the placement of the object with respect to negation, particles and subjects. As we have seen above (table 1), the same variable is sometimes tested in more than one condition of the experiment. In the tables below, the results from the different parts are collapsed, as we find no or little effect of part. The results for NP and pronominal subjects/objects are split up where necessary. For clarity, the two tables both include the information about the relative order of a subject and an object (long object shift).

\begin{tabular}{cccc}
\hline Word order pair & Subject first & Subject second & Other \\
\hline NP Sub. - Neg & 540 & 0 & 33 \\
Pro Sub. - Neg & 556 & 0 & 22 \\
NP Sub. - Part & 614 & 0 & 54 \\
Pro Sub. - Part & 461 & 0 & 23 \\
NP Sub. - Obj. & 821 & 0 & 39 \\
Pro Sub. - Obj. & 553 & 1 & 22 \\
Total & 3545 & 1 & 193 \\
\hline
\end{tabular}

TABLE 3: Placement of subjects with respect to negation, particles and objects.

As table 3 clearly shows, a post-verbal subject always (with one exception) surfaces right after the verb in our elicited material. There is no difference between pronominal and noun phrase subjects. This will be discussed further in section 7. The results for the objects are given in table 4. 


\begin{tabular}{cccc}
\hline Word order pair & Object first & Object second & Other \\
\hline $1^{\text {st }}$ Pro/Refl Obj. - Neg & 526 & 3 & 48 \\
$3^{\text {rd }}$ Pro - Neg & 291 & 24 & 6 \\
NP Obj. - Neg & 11 & 280 & 10 \\
Pro Obj. - Part. & 580 & 0 & 48 \\
NP Obj. - Part. & 649 & 3 & 43 \\
Pro Obj. - Sub. & 1 & 1374 & 61 \\
Total & 2058 & 1684 & 216 \\
\hline
\end{tabular}

TABLE 4: Placement of objects with respect to negation, particles and subjects.

Overall, we see a more varied behavior for the objects compared to the subjects. Objects precede particles and follow subjects, with very few exceptions, independently of the form of the object. The form matters for placement of objects with respect to negation, where pronominal objects tend to precede negation, and NP subjects follow. Here we see a slightly less categorical pattern, where $3^{\text {rd }}$ person pronominal objects sometimes follow a negation (in total, $7.5 \%$ of the times), and a few attestations of NP objects preceding negation (3.65\%).

\section{[7] DISCUSSION:}

OBJECT, SUBJECT AND PARTICLE PLACEMENT IN FAROESE

The results from the Faroese argument placement experiment contain surprisingly little variation. We find no variation in placement of definite or pronominal subjects: both pronominal and NP subjects precede negation (and other adverbs) and direct objects. Neither do we find any variation in the placement of objects with respect to particles: all objects precede particles. For both subject placement and particle placement, the Faroese results look identical to the results from the Danish field work sessions (see also Svenonius 1996, who makes the claim that Faroese and Danish behave similarly with respect to these two properties).

We also see that NP object shift is highly rare, and possibly thematically restricted. It should however be pointed out that NP object shift, although rare in the results, is found more frequently in the Faroese results compared to the Norwegian, Swedish and Danish results, where we only find 1-4 attestations per language, usually in connection with obvious production difficulties (as evident from sound files in the NWD interface). Still, the Faroese results differ radically 
from the results from the Icelandic data collection (see Larsson 2020); here, the results from the same set-up as the one used in the Faroese reveal a more even split between shifted and unshifted NP objects.

We find some attestations of unshifted pronominal objects, mainly third person non-reflexive pronouns. Further research is needed to establish to which extent these examples can be accounted for by appealing to either prosody or semantics. Interestingly, the results from field work with the same method in Norway and Denmark show a similar instability with third person pronominal objects, as opposed to first person singular and reflexive pronouns. The results from the Icelandic fieldwork sessions reveal a much more stable system, where all pronominal objects precede negation. In general, reflexive pronouns and personal pronouns that are form-identical with reflexive pronouns, tend to shift more obligatorily than third person non-reflexive pronouns (i.e., hann/hana/teir - him/her/them). If this is due to information structure or a categorical difference between different types of pronouns is however still not known. As was pointed out in the result section, several of the unshifted third person pronouns appear to be fully unstressed, which suggests that information structure cannot completely explain the variation. The interested reader is encouraged to explore the online database, and make up their own mind about the role of stress, person/number and information structure in the variable object shift cases.

\section{[8] SUMMARY AND REMAINING QUESTIONS}

The most striking result of the experiment is undoubtedly the almost complete lack of variation. Previous literature has suggested that there is some variation within Faroese with respect to definite NP subject placement (Jonas 1993), particle placement (Thráinsson et al. 2012) and NP object shift (Thráinsson 2013). In this study, we found no variation with respect to the two first variables, and for the third variable (NP object shift), the variation is so small that it may be within error margins. Note that this is not just effects of the experimental method or the material used in this study: variation with respect to all three properties mentioned above is found in at least one of the other languages in the NWD: we find a considerable amount of variation with respect to subject placement in Swedish and Norwegian; particle placement in Norwegian and Icelandic; and NP objects in Icelandic. Furthermore, the verb placement experiment reported on in Westendorp (2020), which uses a similar paradigm and partly the same group of participants, revealed plenty of variation, both within and between participants in Faroe Islands. Overall, the results from the Faroese argument placement experiment resemble the results from the field work in Denmark, and differ crucially from Icelandic with respect to (a) the placement of particles with respect 
to objects, and (b) the placement of NP objects with respect to negation.

It is however important to point out that the results from our experiment cannot rule out that there still is variation with respect to all the phenomena mentioned above in Faroese. First, we did not collect any data from the southern islands Sandoy and Suðuroy, where we might find slightly different patterns. Secondly, our test material is limited: we only test subject and object placement with respect to a negation: other adverbs may reveal more variation. Furthermore, as pointed out by Thráinsson (2013), information structure is an important factor in NP object shift, but the experiment contained no direct manipulation of given/new status of either objects or subjects. Still, observe that the same type of items that was used in this test give rise to a high proportion of shifted NP objects in Icelandic, suggesting that NP object shift in Icelandic and Faroese (if it still exists), is governed by partly different factors.

In this article we have not discussed variation, or possibly lack of variation, in prosodic patterns or other phonological/phonetic variation. This is mainly due to the fact that the data has not been acoustically analyzed yet. We hope that this will be done in the near future, but for now, we invite the readers themselves to explore the recordings available in the Nordic Word order Database.

For the reader who wants to know more about variation in present day Faroese, the NORMS special issue Faroese (Svenonius et al. 2009) is a good starting point, and so is the volume Syntactic Variation in Insular Scandinavian (Thráinsson et al. 2017).

\section{AC KNOWLEDGMENTS}

This work would not have been possible without the generous help of Zakaris Svabo Hansen, Jóhannes Gísli Jónsson, Solveig Malmsten and Annika Simonsen who spent considerable time translating and improving our experimental materials; Julian Lysvik who piloted the first experiment; Rakul Absalonsen and Gunnvør Brimnes who helped us recruit and test participants; Filippa Lindahl who joined us for the fieldwork; Anna Katharina Pilsbacher who helped annotate the data; and the Faroese participants who gave of their time to work with us. I also wish to thank the two anonymous reviewers, whose comments on an earlier version helped me improve the article considerably. 


\section{REFERENCES}

Anderssen, Merete, Kristine Bentzen, Guro Busterud, Anne Dahl, Björn Lundquist \& Marit Westergaard. 2018. The acquisition of word order in L2 Norwegian: The case of subject and object shift. Nordic Journal of Linguistics 41-3, 247-274.

Andréasson, Maia. 2007. Satsadverbial, ledföljd och informationsdynamik i svenskan. Göteborgsstudier i nordisk språkvetenskap 7. https://hdl.handle.net/2077/17006

Andréasson, Maia. 2008. Not all objects are born alike: Accessibility as a key to pronominal object shift in Swedish and Danish. In Miriam Butt \& Tracy Holloway King (eds.), Proceedings of LFG08, 26-45. Stanford, CA: CSLI Publication

Barnes, Michael. 1992. Faroese syntax: Achievenemts, goals, and problems. In Jonna Louis-Jensen \& Jóhan Hendrik W. Poulsen (eds.), The Nordic Languages and Modern Linguistics 7, 17-37. Tórshavn Føroya Fróðskaparfelag.

Barnes, Michael P. 2001. Faroese Language Studies. Studia Nordica 5. Novus, Oslo.

Bentzen, Kristine. 2014. Object Shift. Nordic Atlas of Language Structures (NALS) Journal 1. 332-343. https://dx.doi.org/10.5617/nals.5402

Bentzen, Kristine and Merete Anderssen. 2019. The form and position of pronominal objects with non-nominal antecedents in Scandinavian and German. Journal of Comparative Germanic Linguistics 22(2). 169-188. https://doi.org/10.1007/s10828-019-09105-w

Bentzen, Kristine, Piotr Garbacz, Caroline Heycock and Gunnar Hrafn Hrafnbjargarson. 2009. On variation in Faroese verb placement. In Svenonius et al. (eds.), 78-102.

Bobaljik, Jonathan, \& Dianne Jonas. 1996. Subject positions and the roles of TP. Linguistic Inquiry 27. 195-236.

Heycock, Caroline, Antonella Sorace and Zakaris Svabo Hansen. 2010. V-to-I and V2 in subordinate clauses: an investigation of Faroese in relation to Icelandic and Danish. Journal of Comparative German Linguistics 13. 61-97. https://doi.org/10.1007/s10828-010-9035-7

Holmberg, Anders. 1986. Word order and syntactic features in the Scandinavian languages and English. Doctoral dissertation, Stockholm University.

Holmberg, Anders. 1993. Two subject positions in IP in Mainland Scandinavian. Working Papers in Scandinavian Syntax 52. 29-41. 
Jonas, Dianne. 1993. The TP parameter in Scandinavian syntax. In Cecilia Hedlund and Anders Holmberg (eds.), Proceedings of the XIVth Scandinavian Conference of Linguistics and the VIIIth Conference of Nordic and General Linguistics, 3360. Gothenburg Papers in Theoretical Linguistics, Gothenburg University.

Jonas, Dianne. 1996. Clause structure and verb syntax in Scandinavian and English. PhD thesis, Harvard University.

Larsson, Ida. Forthcoming. Argument placement in Icelandic. To appear in NALS special issue on NWD.

Larsson, Ida and Björn Lundquist. 2014. Objektsplacering vid partikelverb i norska dialekter och äldre svenska. In Janne Bondi Johannessen and Kristin Hagen (eds.), Språk i Norge og nabolanda. Oslo: Novus. Pp. 99־-131.

Lundquist, Björn, Ida Larsson, Maud Westendorp, Eirik Tengesdal, and Anders Nøklestad. 2019. Nordic Word Order Database: Motivations, Methods, Material and Infrastructure. Nordic Atlas of Language Structures (NALS) Journal 4(1). 1-33. https://doi.org/10.5617/nals.7529

Mathôt, Sebastiaan, Daniel Schreij, and Jan Theeuwes. 2012. OpenSesame: An open-source, graphical experiment builder for the social sciences. Behavior Research Methods 44(2). 314-324.

Nordic Word order Database [Dataset]. University of Oslo: the Text Laboratory. https://tekstlab.uio.no/nwd

Petersen, Hjalmar P. 2010: The Dynamics of Faroese-Danish Language Contact. Heidelberg: Winter.

Sandøy, Helge. 1976: Laust Samansette Verb i Vestnordisk: Ein samanliknande leddstillingsanalyse for islandsk, frerøysk, og romsdalsmål. Magistergradsavhandling, Universitetet i Oslo.

Svenonius, Peter. 1996. The verb-particle alternation in the Scandinavian languages. Ms. University of Tromsø.

Svenonius, Peter. 2002. Subject positions and the placement of adverbials. In Peter Svenonius (ed.), Subjects, Expletives and the EPP, 201-242. Oxford University Press.

Svenonius, Peter. 2003. Limits on P: filling in holes vs. falling in holes. Nordlyd. Proceedings of the 19th Scandinavian Conference of Linguistics 31 2: 431-445. 
Svenonius, Peter, Kristine Bentzen, Caroline Heycock, Jógvan í Lon Jacobsen, Janne Bondi Johannessen, Jeffrey K. Parrott, Tania E. Strahan, and Øystein Alexander Vangsnes (eds.). 2009. NORMS Papers on Faroese. Nordlyd 36.2.

Thráinsson, Höskuldur. 2009. Looking for parametric correlations within Faroese. In Svenonius et al. (eds.), 1-24.

Thráinsson, Höskuldur. 2013. Full NP Object Shift: The Old Norse Puzzle and the Faroese Puzzle revisited. Nordic Journal of Linguistics, 36(2). 153-186. https://doi.org/10.1017/S033258651300022X

Thráinsson, Höskuldur. 2017. On quantity and quality in syntactic variation studies. In Höskuldur Thráinsson, Caroline Heycock, Hjalmar P. Petersen and Zakaris Svabo Hansen (eds.), Syntactic variation in Insular Scandinavian (Studies in Germanic Linguistics 1), 19-52. Amsterdam: John Benjamins.

Thráinsson, Höskuldur, Hjalmar P. Petersen, Jógvan í Lon Jacobsen and Zakaris Svabo Hansen. 2012. Faroese: An overview and reference grammar. 2nd edn. Fróðskapur Faroe University Press \& Linguistic Institute, University of Iceland.

Thráinsson, Höskuldur, Heycock, Caroline, Petersen, Hjalmar P. and Hansen, Zakaris Svabo (eds.). 2017. Syntactic variation in Insular Scandinavian. Amsterdam/Philadelphia: John Benjamins

Vangsnes, Øystein Alexander. 1995. Referentiality and argument positions in Icelandic. Working Papers in Scandinavian Syntax 55, 89-109.

Westendorp, Maud. 2020. Verb placement in embedded sentences in Faroese. Nordic Atlas of Language Structures (NALS) Journal 5(1). 28-42.

CONTACT

Björn Lundquist

UiT The Arctic University of Norway

bjorn. lundquist@uit.no 